\title{
An unstructured-grid, finite-volume sea ice model: Development, validation, and application
}

\author{
Guoping Gao, ${ }^{1,2}$ Changsheng Chen, ${ }^{1,2}$ Jianhua Qi, ${ }^{1}$ and Robert C. Beardsley ${ }^{3}$
}

Received 28 September 2010; revised 17 May 2011; accepted 16 June 2011; published 17 September 2011.

[1] A sea ice model was developed by converting the Community Ice Code (CICE) into an unstructured-grid, finite-volume version (named UG-CICE). The governing equations were discretized with flux forms over control volumes in the computational domain configured with nonoverlapped triangular meshes in the horizontal and solved using a second-order accurate finite-volume solver. Implementing UG-CICE into the Arctic Ocean finite-volume community ocean model provides a new unstructured-grid, MPI-parallelized model system to resolve the ice-ocean interaction dynamics that frequently occur over complex irregular coastal geometries and steep bottom slopes. UG-CICE was first validated for three benchmark test problems to ensure its capability of repeating the ice dynamics features found in CICE and then for sea ice simulation in the Arctic Ocean under climatologic forcing conditions. The model-data comparison results demonstrate that UG-CICE is robust enough to simulate the seasonal variability of the sea ice concentration, ice coverage, and ice drifting in the Arctic Ocean and adjacent coastal regions.

Citation: Gao, G., C. Chen, J. Qi, and R. C. Beardsley (2011), An unstructured-grid, finite-volume sea ice model: Development, validation, and application, J. Geophys. Res., 116, C00D04, doi:10.1029/2010JC006688.

\section{Introduction}

[2] The Arctic Ocean, connected to the North Atlantic Ocean through the Greenland Sea and Baffin Bay and to the Pacific Ocean through Bering Strait, features both basinand coastal scale ocean processes (Figure 1). Divided by the Lomonosov Ridge, the Eurasia and Canadian Basins are characterized by cyclonic gyres around steep topographic slopes. The water depth over the slope changes abruptly from a few hundred meters to several thousand meters over a distance of a few kilometers. The Canadian Archipelago, located north of mainland Canada and containing many islands, is one of the largest coastal island complexes in the world ocean. This Archipelago functions as a network for the water exchange between the Arctic Ocean and the North Atlantic Ocean [Kliem and Greenberg, 2003; Steiner et al., 2004; Häkkinen and Proshutinsky, 2004] and the tidal energy in Baffin Bay to the Arctic Basin [Kowalik and Proshutinsky, 1994; Chen et al., 2009]. Resolving coastal geometries with numerous islands and narrow passages in the Archipelago and steep bottom topography on the continental slope and ridges has become a critical need for the Arctic Ocean

\footnotetext{
${ }^{1}$ School for Marine Science and Technology, University of Massachusetts Dartmouth, New Bedford, Massachusetts, USA.

${ }^{2}$ Marine Ecosystem and Environment Laboratory, College of Marine Science, Shanghai Ocean University, Shanghai, China.

${ }^{3}$ Department of Physical Oceanography, Woods Hole Oceanographic Institution, Woods Hole, Massachusetts, USA.

Copyright 2011 by the American Geophysical Union. 0148-0227/11/2010JC006688
}

modeling [Proshutinsky et al., 2001, 2005; Proshutinsky and Kowalik, 2007; Panteleev et al., 2007; Golubeva and Platov, 2007].

[3] The Arctic Ocean unstructured-grid, finite-volume community ocean model (hereafter referred to as AO-FVCOM) has been developed with an aim to provide better resolution of the complex geometry in this region [Chen et al., 2009, Gao et al., 2010]. To simulate ice-current interaction processes, the Los Alamos Community Ice Code (CICE) was converted into an unstructured-grid, finite-volume version under the FVCOM framework (hereafter referred to as UG-CICE) and implemented into AO-FVCOM. CICE is governed by energy-conserving thermodynamics equations with four layers of ice and one layer of snow in each of five ice categories [Hunke and Lipscomb, 2006], elastic-viscousplastic ice momentum equations [Hunke and Dukowicz, 1997, 2002; Hunke, 2001], and energy-based ridging schemes of Thorndike et al. [1975], Hibler [1979], and Lipscomb et al. [2007] as well as ice strength parameterizations given by Rothrock [1975]. The original CICE was designed as a module of the Community Climate System Model (CCSM) to couple with the structured-grid ocean model called the Parallel Ocean Program (POP) [http://www.ccsm.ucar.edu/]. The realistic performance and accuracy of CICE has encouraged its use as a community ice model which has been implemented into other structured-grid ocean models such as MITgcm, HYCOM, and NEMO [Hunke and Lipscomb, 2006].

[4] Unlike the differential forms used in structured-grid finite difference models, UG-CICE discretizes the integral forms of the governing equations and solves them numeri- 


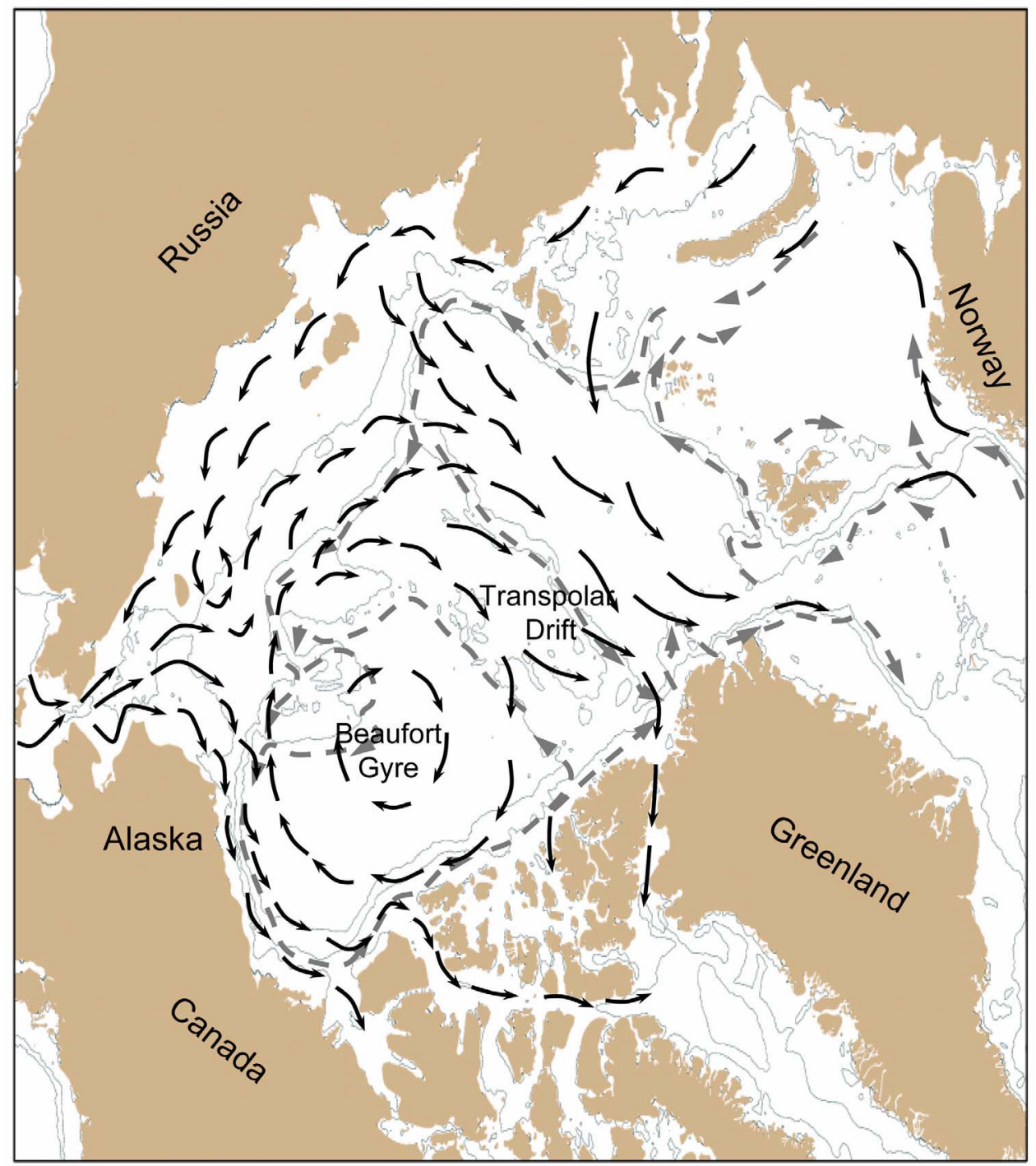

Figure 1. Bathymetry and schematic of near-surface and deep circulation in the Arctic region. Contour lines are 50,500, and $2000 \mathrm{~m}$. Solid black arrows are the near-surface circulation; dashed gray vectors are the deep circulation. Redrawn following the schematic of the circulation of Proshutinsky et al. [2005].

cally by flux calculations over nonoverlapped triangular meshes. This finite-volume approach is better at guaranteeing mass conservation in both individual control volumes and the entire computational domain [Chen et al., 2003, 2007; Huang et al., 2008]. In view of this technical approach, UG-CICE combines the best attributes of finite difference methods for simple discrete computational efficiency and finite element methods for geometric flexibility. Because sea ice processes play a major role in the Arctic Ocean and the numerical algorithms used to solve UG-CICE differ significantly from CICE, validation experiments are needed to demonstrate the capability and accuracy of UG-CICE to resolve the ice dynamics and kinematics in the Arctic Ocean.

[5] This paper summarizes the validation experiment results with the focus on comparisons with CICE for three idealized benchmark test problems and with observational data in an application to the Arctic Ocean. The rest of the paper is organized as follows. The governing equations and finite-volume discrete algorithms of UG-CICE are described in section 2. The validation experiment results for the benchmark test problems are presented and discussed in section 3. The results of using the coupled UG-CICE and AO-FVCOM to simulate the Arctic Ocean under climatologic forcing conditions are given in section 4 . Some critical issues in the ice model evaluation are discussed in section 5, and then conclusions are summarized in section 6 .

\section{Governing Equations and Finite-Volume Discrete Algorithms of UG-CICE}

\subsection{Governing Equations}

[6] UG-CICE uses the same governing equations as CICE. UG-CICE is coded for both spherical and Cartesian 
coordinates. For simplification, only the Cartesian coordinate system is described. The full nonlinear ice momentum equations are given as

$$
\left\{\begin{array}{l}
m \frac{\partial u}{\partial t}+m\left(u \frac{\partial u}{\partial x}+v \frac{\partial u}{\partial y}\right)-m f v=\frac{\partial \sigma_{1 j}}{\partial x_{j}}-m g \frac{\partial H_{0}}{\partial x}+\tau_{a x}+\tau_{w x} \\
m \frac{\partial v}{\partial t}+m\left(u \frac{\partial v}{\partial x}+v \frac{\partial v}{\partial y}\right)+m f u=\frac{\partial \sigma_{2 j}}{\partial x_{j}}-m g \frac{\partial H_{0}}{\partial y}+\tau_{a y}+\tau_{w y}
\end{array},\right.
$$

where $m$ is the combined mass of ice and snow per unit area; $u$ and $v$ are the $x$ and $y$ components of the ice velocity; $f$ is the Coriolis parameter; $g$ is gravity; $H_{o}$ is the sea surface elevation; $\sigma_{i j}$ is the internal stress tensor with subscripts of 1 , 2 and $i, j$ (in a range from 1 to 2 ) representing $x$ (noted as "1") and $y$ (noted as " 2 ") components; $\left(\tau_{a x}, \tau_{a y}\right)$ and $\left(\tau_{w x}\right.$, $\left.\tau_{w y}\right)$ are the $x$ and $y$ components of sea surface wind and water stresses, respectively. The vector forms of these stresses follow Connolley et al. [2004], which are formulated as

$$
\begin{gathered}
\vec{\tau}_{a}=c C_{a} \rho_{a}\left|\vec{u}_{a}\right|\left(\vec{u}_{a} \cos \phi+k \times \vec{u}_{a} \sin \phi\right) \\
\vec{\tau}_{w}=c C_{w} \rho_{w}\left|\vec{u}_{w}-\vec{u}\right|\left[\left(\vec{u}_{w}-\vec{u}\right) \cos \theta+\vec{k} \times\left(\vec{u}_{w}-\vec{u}\right) \sin \theta\right],
\end{gathered}
$$

where $c$ is the ice concentration ranging from 0 to $1 ; \vec{u}$ is the surface velocity vector; $C$ is the drag coefficient; $\rho$ is the density; and $\phi$ and $\theta$ are the air and water turning angles, respectively. The subscripts " $a$ " and " $w$ " represent the "air" and "water," respectively.

[7] In the elastic-viscous-plastic (EVP) dynamics system [Hunke and Dukowicz, 1997], $\sigma_{i j}$ is derived from the equation as

$$
\frac{1}{E} \frac{\partial \sigma_{i j}}{\partial t}+\frac{1}{2 \eta} \sigma_{i j}+\frac{\eta-\zeta}{4 \eta \zeta} \sigma_{k k} \delta_{i j}+\frac{P}{4 \zeta} \delta_{i j}=\dot{\epsilon}_{i j}
$$

where $E$ is the elastic parameter defined by Young's modulus given as $E=\zeta / T ; \zeta$ is the bulk viscosity; $T$ is a damping timescale for elastic waves; $\eta$ is the shear viscosity; $P$ is the ice strength; $\in_{i j}$ is the ice strain rate; $k$ represents $i$ or $j$; and $\delta_{i j}$ is the Kronecker function defined as $\delta_{i j}=1$ for $i=j$ and 0 for $i \neq j . \in_{i j}$ has the form of

$$
\dot{\epsilon}_{i j}=\frac{1}{2}\left(\frac{\partial u_{i}}{\partial x_{j}}+\frac{\partial u_{j}}{\partial x_{i}}\right)
$$

[8] $P$ can be estimated with options of two empirical formulas derived by Hibler [1979] or Rothrock [1975] and Lipscomb et al. [2007]. From Hibler [1979],

$$
P=P^{*} h \exp \left[-C^{*}(1-c)\right]
$$

where $P^{*}=2.75 \times 10^{4} \mathrm{~N} / \mathrm{m}^{2}, h$ is the mean ice thickness, and $C^{*}=20$ is an empirical constant. From Lipscomb et al. [2007],

$$
P=C_{f} C_{p} \beta \sum_{n=1}^{N_{c}}\left[-a p_{n} h_{n}^{2}+\frac{a p_{n}}{k_{n}}\left(H_{\mathrm{min}}^{2}+2 \lambda H_{\min }+2 \lambda^{2}\right)\right],
$$

where $C_{f}$ is an empirical parameter for frictional energy dissipation; $C_{p}=(g / 2)\left(\rho_{i} / \rho_{w}\right)\left(\rho_{w}-\rho_{i}\right) ; \rho_{i}$ is the ice density; $\beta=R_{\mathrm{tot}} / R_{\mathrm{net}}>1 ; R_{\mathrm{tot}}=\sum_{n=1}^{N_{c}} r_{n}, r_{n}$ is the ridging rate; $N_{c}$ is the total number of ice categories; $n$ is the number of each category from 1 to $N_{c}, R_{\text {net }}$ is the net rate of area loss for the ice pack; $a p_{n}$ is the thickness distribution of the ice participating in ridging; $h_{n}$ is the ice thickness for the category $n$; $k_{n}$ is the ratio of the mean ridge thickness to the thickness of ridging ice; $H_{\min }=2 h_{n}$; and $\lambda$ is an empirical $e$-folding scale.

[9] In the viscous-plastic (VP) rheology, $\sigma_{i j}$ is a function of the ice strain rate and strength by the constitutive law [Hibler, 1979; Zhang and Hibler, 1997], which can be computed using (4) under steady state conditions.

[10] The ice transport equation satisfies the conservation law by which the thickness distribution function remains unchanged following the ice current trajectory. Define that $\hat{g}(\vec{x}, h, t)$ is the thickness distribution function containing the ice area, ice volume, snow volume, ice energy, snow energy and area-weighted surface temperature, the transport equation for $\hat{g}$ can be written as the standard advection equation

$$
\frac{\partial \hat{g}}{\partial t}=-\nabla \cdot(\hat{g} \vec{u})
$$

[11] In spherical coordinates, the $x$ (eastward) and $y$ (northward) axes are defined as

$$
x=r \cos \varphi\left(\lambda-\lambda_{0}\right) \text { and } y=r\left(\varphi-\varphi_{0}\right),
$$

where $r$ is the earth's radius; $\lambda$ is longitude; $\varphi$ is latitude, and $\lambda_{0}$ and $\varphi_{0}$ are the reference longitude and latitude, respectively. Following the coordinate module in FVCOM [Chen et al., 2006], equations (1)-(8) can be easily converted into the spherical coordinate system.

\subsection{Discretization}

[12] Following the FVCOM framework, equations (1)-(8) are discretized in the horizontal using a set of nonoverlapped unstructured triangular meshes that subdivide the model domain. A triangle is composed of three nodes; a centroid and three sides (Figure 2), on which $u$ and $v$ are placed at centroids and scalar variables like $\hat{g}$ are placed at nodes. $u$ and $v$ at centroids are calculated based on the net flux through the three sides of that triangle (called the momentum control element: MCE), while scalar variables at each node are determined by the net flux through the sections linked to centroids and the middle point of the sideline in the surrounding triangles (called the tracer control element: TCE).

[13] Integrating equations (1) and (4) over individual MCE area gives

$$
\begin{aligned}
\frac{\partial u}{\partial t}= & -\frac{1}{\Omega}\left[\oint_{s^{\prime}} u \bar{v}_{n} d s^{\prime}+\iint_{\Omega} f v d x d y+\frac{1}{m} \oint_{s^{\prime}}\left(-\sigma_{11} d y+\sigma_{12} d x\right)\right. \\
& \left.-g \oint_{s^{\prime}} H_{o} d y+\iint_{\Omega} \frac{\tau_{a x}+\tau_{w x}}{m} d x d y\right], \\
\frac{\partial v}{\partial t}= & -\frac{1}{\Omega}\left[\oint_{s^{\prime}} v \bar{v}_{n} d s^{\prime}-\iint_{\Omega} f u d x d y+\frac{1}{m} \oint_{s^{\prime}}\left(-\sigma_{12} d y+\sigma_{22} d x\right)\right. \\
& \left.-g \oint_{s^{\prime}} H_{o} d x+\iint_{\Omega} \frac{\tau_{a x}+\tau_{w x}}{m} d x d y\right],
\end{aligned}
$$


a.

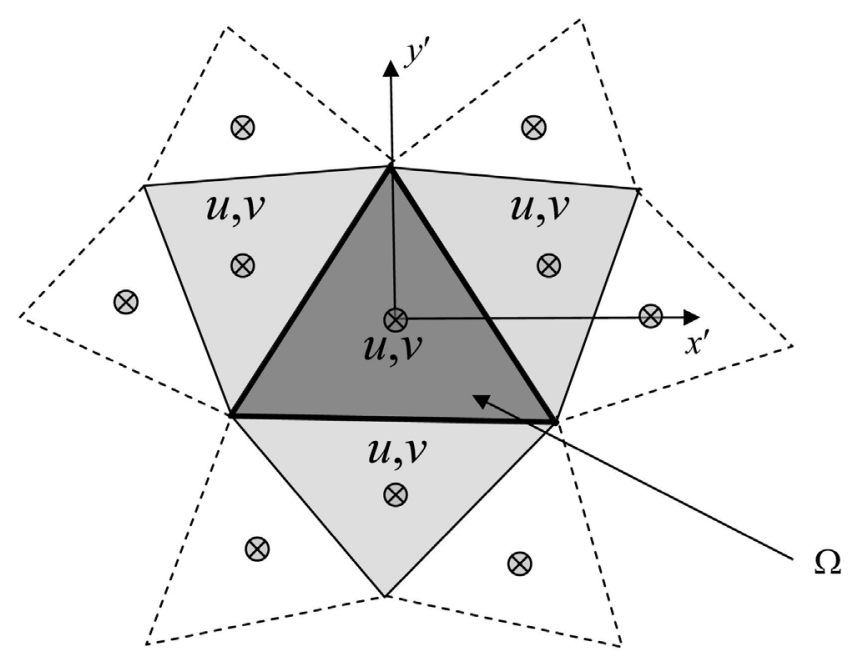

b.

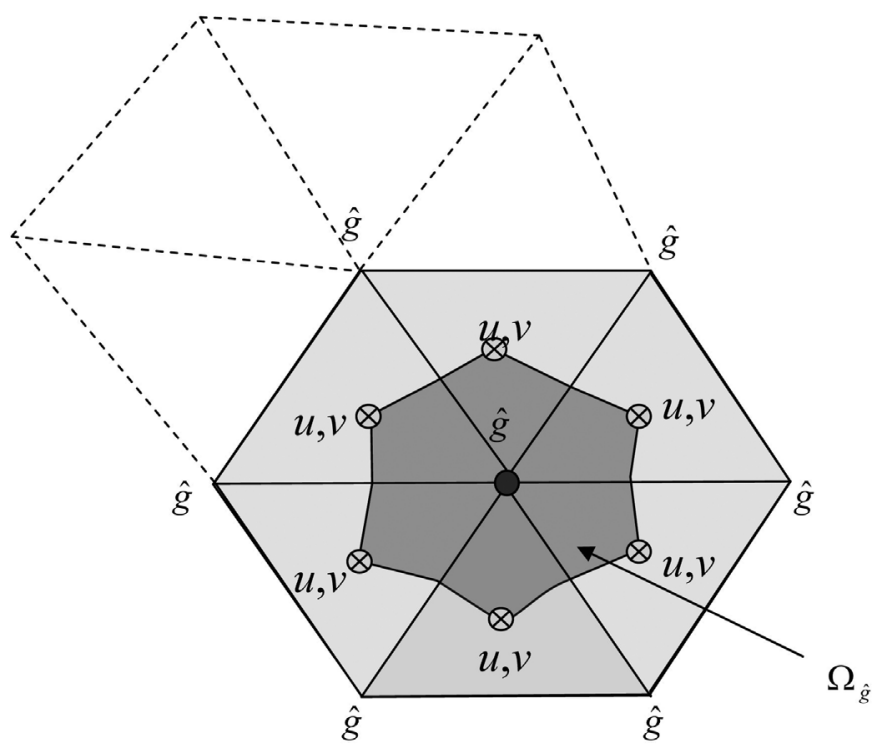

Figure 2. Schematic of the unstructured triangular grid used for geographical spatial discretization in UG-CICE ((a) for the ice momentum equation and (b) for the ice transport equation). Definitions of variables are provided in the text.

$$
\begin{gathered}
\frac{\partial \sigma_{1}}{\partial t}+\frac{\sigma_{1}}{2 T}+\frac{P}{2 T}=\frac{P}{2 T \Delta} D_{D} \\
\frac{\partial \sigma_{2}}{\partial t}+\frac{e^{2} \sigma_{2}}{2 T}=\frac{P}{2 T \Delta} D_{T} \\
\frac{\partial \sigma_{12}}{\partial t}+\frac{e^{2} \sigma_{12}}{2 T}=\frac{P}{4 T \Delta} D_{S}
\end{gathered}
$$

where $\bar{v}_{n}$ is the velocity component normal to the sides of the triangle and $s^{\prime}$ is the closed trajectory composed of the three sides. $\sigma_{1}=\sigma_{11}+\sigma_{22}, \sigma_{2}=\sigma_{11}-\sigma_{22}, D_{D}=\dot{\epsilon}_{11}+\dot{\epsilon}_{22}$,
$D_{T}=\dot{\epsilon}_{11}-\dot{\epsilon}_{22}, D_{S}=2 \dot{\epsilon}_{12}, \Delta=\left[D_{D}^{2}+\frac{1}{e^{2}}\left(D_{T}^{2}+D_{S}^{2}\right)\right]^{1 / 2}$, and $e=2$ is the ratio of major to minor axis of the elliptical yield curve for the principal components of the stress. In the EVP system, the internal stress is a function of the time- and space-satisfying tensor equations in equations (12)-(14), which requires a shorter time step to resolve elastic waves. Because the ice strain rates in these three equations are related to the ice velocity, equations (10)-(14) need to be integrated at the same time step. In the thermodynamics and ice transport time step $(\Delta t)$, equations (10)-(14) are integrated at the subcycling time step of $\Delta t_{e}=\Delta t / N_{d}$, where $N_{d}=120$ is the default subintegration number in the UG-CICE as CICE. 

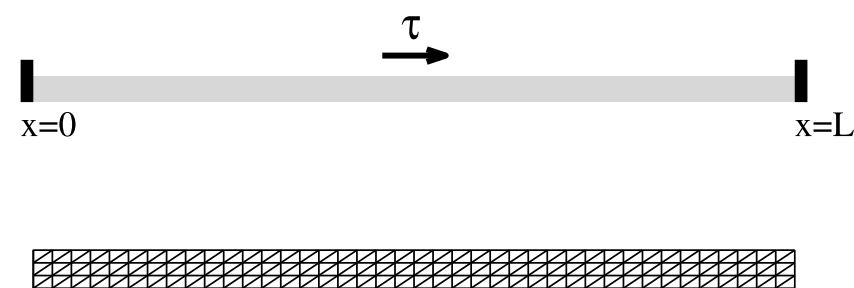

$\mathrm{x}=0$

$\mathrm{X}=\mathrm{L}$

Figure 3. Schematic of the rectangular domain and triangular grid used for a 1-D steady state test problem.

[14] Equations (12)-(14) are discretized in a semi-implicit form given as

$$
\left\{\begin{array}{l}
\frac{\sigma_{1}^{\hat{n}+1}-\sigma_{1}^{\hat{n}}}{\Delta t_{e}}+\frac{\sigma_{1}^{\hat{n}+1}}{2 T}+\frac{P}{2 T}=\frac{P}{2 T \Delta^{n}} D_{D}^{\hat{n}} \\
\frac{\sigma_{2}^{\hat{n}+1}-\sigma_{2}^{\hat{n}}}{\Delta t_{e}}+\frac{e^{2} \sigma_{2}^{\hat{n}+1}}{2 T}=\frac{P}{2 T \Delta^{n}} D_{T}^{\hat{n}} \\
\frac{\sigma_{12}^{\hat{n}+1}-\sigma_{12}^{\hat{n}}}{\Delta t_{e}}+\frac{e^{2} \sigma_{12}^{\hat{n}+1}}{2 T}=\frac{P}{4 T \Delta^{n}} D_{S}^{\hat{n}}
\end{array},\right.
$$

so that $\sigma_{11}^{\hat{n}+1}=0.5\left(\sigma_{1}^{\hat{n}+1}+\sigma_{2}^{\hat{n}+1}\right)$ and $\sigma_{22}^{\hat{n}+1}=0.5\left(\sigma_{1}^{\hat{n}+1}-\right.$ $\left.\sigma_{2}^{\hat{n}+1}\right)$.

[15] We adopted the second-order upwind scheme in FVCOM to solve equations (10) and (11). This finitevolume algorithm has been well described by Kobayashi et al. [1999] and Chen et al. [2003, 2006] and a brief description are given here. Let $R_{u}$ and $R_{v}$ represent all the terms on the right of the $u$ and $v$ in equations (10) and (11), respectively, and superscript $\hat{n}$ represents the $\hat{n}$ th time step within $N_{d}$ step integration. In $R_{u}$ and $R_{v}$, the internal stress terms are expressed implicitly at the $(\hat{n}+1)$ th time step. Equations (10) and (11) with an implicit form of internal stresses are integrated numerically from the $\hat{n}$ th time step to $(\hat{n}+1)$ th time step using the modified fourth-order RungeKutta time stepping scheme with second-order accuracy [Chen et al., 2003]. The procedure of the integration is given as

$$
\left\{\begin{array}{l}
u_{R}^{0}=u^{\hat{n}} ; v_{R}^{0}=v^{\hat{n}} ; R_{u}^{0}=R_{u}^{\hat{n}} ; R_{v}^{0}=R_{v}^{\hat{n}} ; \\
u_{R}^{k}=u_{R}^{0}-\alpha^{k} \frac{\Delta t_{e} R_{u}^{k-1}}{4 \Omega} ; v_{R}^{k}=v_{R}^{0}-\alpha^{k} \frac{\Delta t_{e} R_{v}^{k-1}}{4 \Omega}, \\
u^{\hat{n}+1}=u_{R}^{4} ; v^{\hat{n}+1}=v_{R}^{4}
\end{array}\right.
$$

where $k=1,2,3,4$ and $\left(\alpha^{1}, \alpha^{2}, \alpha^{3}, \alpha^{4}\right)=(1 / 4,1 / 3,1 / 2,1) . \Omega$ is the triangular area of the MCE where $u$ and $v$ are located. After the ice velocity is integrated from equation (16) at a subcycling step $\left(\Delta t_{e}\right)$, the divergence terms, strain rates and viscosity can be updated for the next subcycling integration of equation (15). The ice mass $m$, ice strength $P$ and external wind and ocean stress do not change in the thermodynamics time step $(\Delta t)$.

[16] The ice transport equation (8) is calculated in the integral form using the second-order upstream scheme. Integrating (8) over a TCE, we have

$$
\frac{\partial \hat{g}}{\partial t}=-\iint_{\Omega_{\hat{g}}} \nabla \cdot(\hat{g} \vec{u}) d x d y=-\oint_{l_{\Omega_{\hat{g}}}} \hat{g} v_{n} d s,
$$

where $\hat{\Omega}_{\hat{g}}$ is the area of a TCE; the normal velocity $v_{n}$ at the boundary of a TCE is given at each triangular centroid, and $\hat{g}$ at the boundary is calculated by linear interpolation from the upwind control volume shown in Figure 2 where $\hat{g}=\hat{g}_{t}+\frac{\partial \hat{g}}{\partial x} \Delta x+\frac{\partial \hat{g}}{\partial y} \Delta y ; \quad \frac{\partial \hat{g}}{\partial x}=\frac{1}{\hat{\Omega}_{\hat{g}}} \oint g \hat{d} y ; \quad \frac{\partial \hat{g}}{\partial y}=\frac{1}{\hat{\Omega}_{\hat{g}}} \oint \hat{g} d x$, where $\hat{\Omega}_{\hat{g}}$ is the area of the control volume in the upwind direction. A detailed explanation of the second-order upwind scheme used in the tracer calculation is given by Chen et al. [2006].

\subsection{Coupling of UG-CICE and AO-FVCOM}

[17] We have implemented UG-CICE into AO-FVCOM. The coupling of these two models is at the ice-ocean interface with ice mass, ice stress, and heat exchange. Salt was treated as a conservative mass. The AO-FVCOM is a free surface model and in the ice-free ocean, the salt flux is zero at the sea surface. The precipitation minus evaporation $(P-E)$ at the surface provides freshwater into the ocean, which changes the salt concentration and the sea surface vertical velocity but not the salt flux at the air-sea interface. In the ice cover ocean, the local change of the ice mass per unit area in UG-CICE and AO-FVCOM is added to the kinematic condition of vertical velocity at the ice-ocean interface. In the ice model, the ice-ocean salt flux is calculated with an assumption of a constant reference salt concentration of 4 PSU in ice. The salt flux at the ice-ocean interface of UG-CICE and AO-FVCOM considers the variation of the total salinity change related to the ice volume change.

\section{Validation Experiments for Idealized Cases}

[18] Three idealized benchmark test cases were selected to validate UG-CICE via comparison with CICE. In CICE, these test cases were designed to compare the EVP and VP models, the ridging scheme and its instability, and ice-current interaction in high and low ice concentration regimes, respectively. We have repeated these three experiments to test the capability of UG-CICE to capture the same structure predicted by CICE in the structured-grid-based domain.

\subsection{A 1-D Steady State Solution}

[19] Consider a one-dimensional (1-D) domain $(0, L)$ bounded by two solid walls (Figure 3 ). Under steady state conditions, the gradient of the ice velocity in this domain at time step $\mathrm{n}+1$ can be written as the analytic expression [Hunke and Dukowicz, 1997]

$$
\frac{\partial u^{n+1}}{\partial x}=\left\{\begin{array}{lll}
G P^{\prime} / \zeta_{\max } & \text { if } & \zeta>\zeta_{\max } \\
G\left|\frac{\partial u^{n}}{\partial x}\right| & \text { if } & \zeta_{\min }<\zeta<\zeta_{\max }, \\
G P^{\prime} / \zeta_{\min } & \text { if } & \zeta<\zeta_{\min }
\end{array}\right.
$$

where $P^{\prime}=P / \sqrt{5} ; G=\frac{4 \tau}{\sqrt{5} P}\left(\frac{L}{2}-x\right) ; x$ is the horizontal coordinate; $n$ is the time step for numerical integration; $u$ is the ice velocity in the $x$ direction; $\tau$ is the total external stress exerted on the ice surface, and the subscripts "max" and "min" of $\zeta$ indicate the maximum and minimum bulk viscosities. The steady state solution for $u$ can be calculated by iteration under given forcing and boundary conditions. The solution is composed of three line segments, the inner 


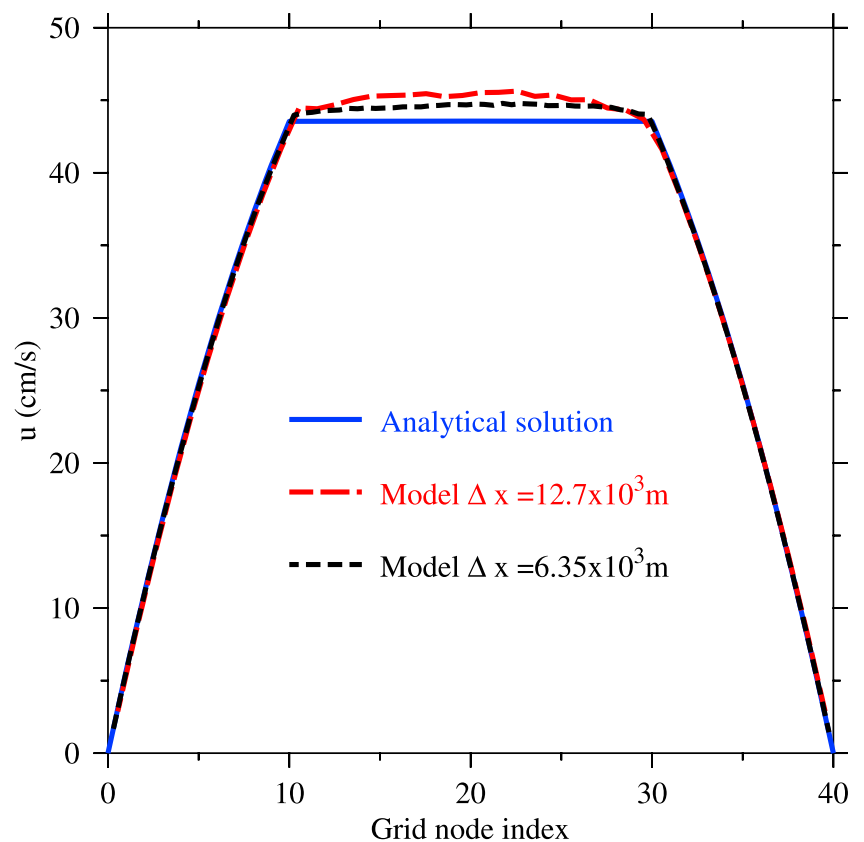

Figure 4. The comparison of the along-channel distributions of ice velocities $(u)$ derived by the UG-CICE and analytical solution.

section characterized by $\zeta_{\max }$, the two outer sections by $\zeta_{\min }$, and transition sections from inner to outer in which $\zeta$ change from $\zeta_{\max }$ to $\zeta_{\min }$.

[20] Following Hunke and Dukowicz [1997] with the ice concentration of 0.9 , the thick ice thickness of $0.6 \mathrm{~m}$, the thin ice thickness of $0.1 \mathrm{~m}$, and the snow thickness of $0.1 \mathrm{~m}$, and forcing $\tau$ of $0.9 \mathrm{~kg} / \mathrm{m} / \mathrm{s}^{2}$, ice strength $P$ calculated with equation (6) everywhere, the analytical solution for $u$ can be calculated by integrating equation (18) through iteration for a given initial condition of $u=0, \zeta=\zeta_{\max }$ everywhere, with $\Delta x=12.7 \times 10^{3} \mathrm{~m}$. The ice velocity in equation (18) reaches a steady state solution in 200 iterations (with error of ice velocity less than $10^{-5} \mathrm{~cm} / \mathrm{s}$ ). To set up a 2-D model for a 1-D experiment, we first configured the computational domain by 4 uniform squares in the $y$ direction and $L / \Delta \mathrm{x}$ in the $x$ direction, with a periodic condition in the $y$ direction to ensure no gradients for all variables in this direction. $L$ is $58.8 \mathrm{~km}$. The triangular grid is simply created by dividing an individual square through its diagonal line. Two experiments were conducted for horizontal resolutions of $\Delta x=$ $12.7 \times 10^{3} \mathrm{~m}$ and $6.35 \times 10^{3} \mathrm{~m}$. For both cases, the parameters were specified following the Hunke and Dukowicz [1997] analytical solution. The time step is $40 \mathrm{~s}$ for both cases, and the model reaches steady state over a day. The results given here show the solution at the end of $24 \mathrm{~h}$ integration.

[21] The steady state analytical solution for the ice velocity is the solid line symmetric curve shown in Figure 4: increasing rapidly over a distance of $10 \mathrm{~km}$ from the origin, remaining a constant between 10 and $30 \mathrm{~km}$ and then decreasing rapidly toward the right wall over a distance of $10 \mathrm{~km}$. In Figure 4, the two dashed lines are the result for both high- and low-resolution cases. UG-CICE-predicted ice velocity matches accurately with the analytical solution within the transition zones connected to both walls. As also seen in the results of CICE [Hunke and Dukowicz, 1997], UG-CICE shows a slight overshooting in the interior constant velocity zone. This overshooting is reduced quickly as the horizontal resolution is increased. We note that the analytical solution displayed in Figure 4 of Hunke and Dukowicz [1997] was smaller than the CICE-predicted ice velocity. That analytical solution shown in their paper was not a fully steady state solution. That solution is close to a value with 30 iterations, which is much smaller than the iteration number $(\mathrm{IT}=140)$ recommended by them. After this correction, UG-CICE- and CICE-predicted ice velocities show the same accuracy compared with the analytical solution. A slight difference was noticed between CICE and UG-CICE at the two-zone transition where CICE seems a little more diffusive than UG-CICE. This suggests that the finite-volume algorithm used in UG-CICE better resolves the sharp velocity change in the transition zone [Chen et al., 2003, 2007; Huang et al., 2008].

\subsection{A 1-D Ice Transport and Ridging Problem}

[22] Consider a one-dimensional problem with the domain similar to that shown in Figure 3. The domain is initially covered by a uniform distribution of ice. The ice has a mean thickness of $2.73 \mathrm{~m}$, which consists of five categories with fractions of $(0.05,0.1,0.3,0.35,0.2)$. A wind is specified to blow from west to east at a speed of $10 \mathrm{~m} / \mathrm{s}$. Under these conditions, the governing equation for the ice velocity can be simplified to

$$
m \frac{\partial u}{\partial t}=\tau_{x}-C_{w} u-\frac{(\alpha+1)}{2} \frac{\partial P}{\partial x},
$$

where the definitions of variables in equation (19) are described in section $2, \alpha=\sqrt{1+1 / e^{2}}$ is the parameter measuring the standard yield curve, and $e=2$. As a steady state is reached, the ice velocity satisfies the analytical expression

$$
u=\frac{1}{C_{w}}\left[\tau_{x}-\frac{(\alpha+1)}{2} \frac{\partial P}{\partial x}\right] .
$$

[23] Under free-drifting conditions where $\partial P / \partial x=0, u=$ $\tau_{x} / c_{w}$. In the wind-induced convergence zone near the boundary, $\tau_{x}>C_{w} u$, thus $\partial P / \partial x>0$. This case was used by Lipscomb et al. [2007] to examine the CICE ridging scheme and its stability. Using the same parameters, we reran this case for comparison with CICE. $P$ in equation (19) is determined using equation (7).

[24] When forced by a westerly constant wind, the ice begins to drift freely toward the east. As the ice starts piling up toward the eastern wall, $P$ and the ice stress gradient increase. A steady state can be reached when $P$ is balanced by the wind stress. In this state, the ice velocity vanishes everywhere.

[25] Driven by the same forcing in the rectangular domain, UG-CICE results were almost identical to CICE's presented by Lipscomb et al. [2007]. Figure 5 presents the distributions of $u$ (Figure 5, top) and $P$ (Figure 5, bottom) at days 1,5 , and 30 . At day $1, u$ exhibits a peak of $\sim 17 \mathrm{~cm} / \mathrm{s}$ near the western wall, drops to $\sim 10 \mathrm{~cm} / \mathrm{s}$ rapidly and remains at this order in most of the interior area, and then decreases to zero toward the eastern wall. Correspondingly, 

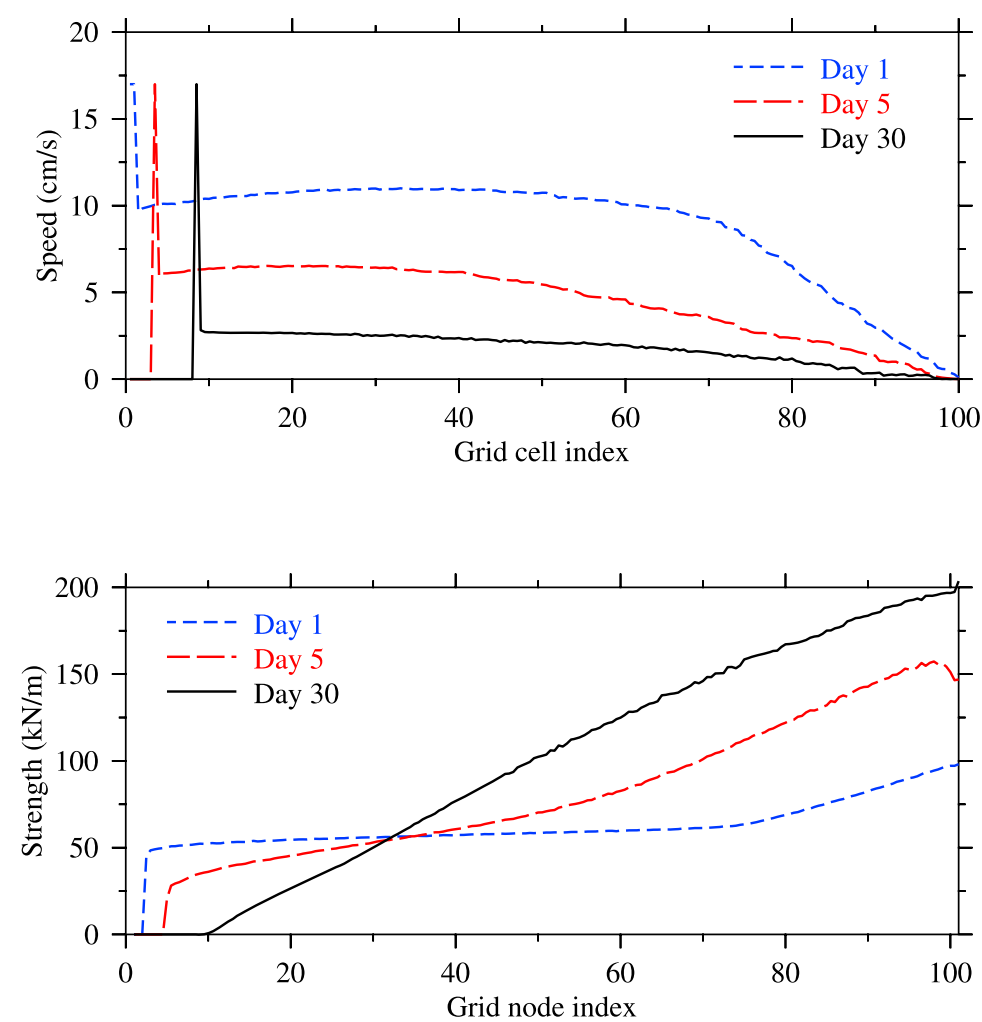

Figure 5. Along-channel distributions of the UG-CICE-calculated ice velocity $(u)$ and strength $(P)$ at model days 1,5 , and 30 .

$P$ remains zero on the western side of the peak velocity, rapidly increases to $50 \mathrm{kN} / \mathrm{m}$ at the peak velocity and remains this order in the interior, and then increases toward the eastern wall as $u$ decreases. As the time integration increases, $u$ in the interior gradually decreases and the $u$ peak remains the same and shifts eastward. As a result, the magnitude and gradient of $P$ increase with $u$ decreases. At day $30, P$ reaches $200 \mathrm{kN} / \mathrm{m}$ on the eastern wall. The capability of UG-CICE to reproduce the CICE's results indicates that UG-CICE has the same accuracy and reliability as CICE in the same structured-grid domain.

\subsection{Current-Ice Interactions in Distinct Ice Concentration Regimes}

[26] We next consider a circular domain with radius $R$ for this test problem. The water velocity is specified as

$$
\left\{\begin{array}{l}
u_{w}=0.1(y-R) / R \\
v_{w}=-0.1(x-R) / R
\end{array},\right.
$$

where $x$ and $y$ are the coordinates defined as $0 \leq x \leq 2 R$ and $0 \leq y \leq 2 R\left(2 \mathrm{R}=1.28 \times 10^{3} \mathrm{~km}\right)$. On a $f$ plane, the surface stress can be expressed as

$\left\{\begin{array}{l}\tau_{x}=\tau_{a x}+C_{w} \rho_{w}\left|\vec{u}_{w}-\vec{u}\right|\left[\left(u_{w}-u\right) \cos \theta-\left(v_{w}-v\right) \sin \theta\right]+m f v \\ \tau_{y}=\tau_{a y}+C_{w} \rho_{w}\left|\vec{u}_{w}-\vec{u}\right|\left[\left(v_{w}-v\right) \cos \theta+\left(u_{w}-u\right) \sin \theta\right]-m f u\end{array}\right.$ where $u$ and $v$ are the $x$ and $y$ components of the ice velocity, $\rho_{w}$ is the water density, and $\theta$ is the angle between water and ice current vectors. The $x$ and $y$ components of the surface wind stress are defined as

$$
\left\{\begin{array}{l}
\tau_{a x}=c C_{a} \rho_{a}\left|\vec{v}_{a}\right|\left(u_{a} \cos \phi-v_{a} \sin \phi\right) \\
\tau_{a y}=c C_{a} \rho_{a}\left|\vec{v}_{a}\right|\left(u_{a} \sin \phi+v_{a} \cos \phi\right)
\end{array},\right.
$$

where $C_{a}$ is the air drag coefficient, $\rho_{a}$ is the air density, $c$ is the ice coverage index (ice concentration) that varies from 0 at the west boundary $(x=0)$ to 1 at the east boundary $(x=2 \mathrm{R})$, and $\phi$ is the angle between the wind direction and the wind stress vector on the ice. In this case, the wind is assumed to be constant and blows from the southwest, with $x$ and $y$ components of $5 \mathrm{~m} / \mathrm{s}$.

[27] Ignoring the surface tilting, the ice momentum equations are given as

$$
\left\{\begin{array}{l}
m \frac{\partial u}{\partial t}=\frac{\partial \sigma_{1 j}}{\partial x_{j}}+\tau_{x} \\
m \frac{\partial v}{\partial t}=\frac{\partial \sigma_{2 j}}{\partial x_{j}}+\tau_{y}
\end{array}\right.
$$

[28] The forcing conditions specified in this problem are the same as those of Hunke [2001]. The only difference is that CICE was tested for a square domain while here we use a circular domain. The experiments were conducted for two cases. The first is the free drifting case without inclusion of the internal ice stress. In this case, the ice is driven by the 

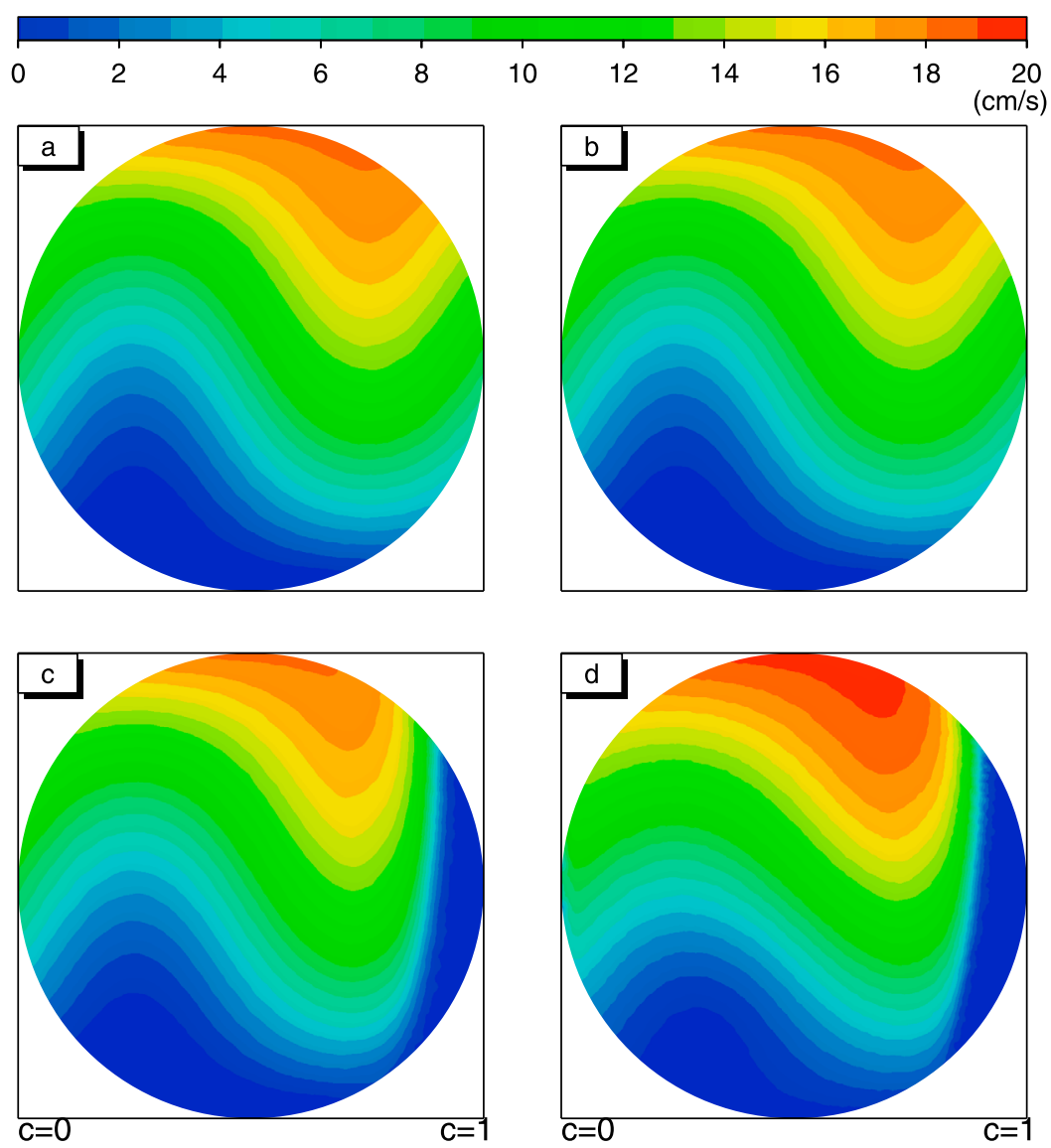

Figure 6. The distribution of the $x$ component of the ice velocity $(u)$ for given $\phi=\theta=25^{\circ}$ and the water current velocity specified by equation (18). (a) UG-CICE-computed for the free drifting case, (b) the analytical solution for the free drifting case, (c) UG-CICE result at the end of fifth day for the case including internal ice stress, and (d) the same as Figure 6c except adding the Coriolis force.

wind via ocean currents and a steady state can be reached when the wind stress is balanced by the ocean-ice stress. Ignoring the Coriolis force, an analytical solution for $u$ and $v$ can be derived for the steady state. The second is the case with inclusion of the internal ice stress under the same external forcing condition. In this case, we also consider the cases with and without Coriolis force.

[29] The initial ice concentration $c$ increases linearly from 0 at $x=0$ to 1 at $x=2 R$, with all existing ice having a uniform thickness of $2 \mathrm{~m}$. When driven by a constant wind, this domain features two distinct dynamical regimes. In the lower ice concentration area, the internal ice stress is small and the ice movement almost features free drifting. In the high ice concentration area, the current-ice interaction cannot be neglected and the ice movement can differ significantly from free drift.

[30] For the free-drifting case, with no Coriolis force and sea surface gradient, ice movement can reach a steady state when the wind stress is balanced by the net ice-ocean stress. In this state, equation (24) can be simplified to

$$
\left\{\begin{array}{l}
\tau_{a x}+C_{w} \rho_{w}\left|\vec{u}_{w}-\vec{u}\right|\left[\left(u_{w}-u\right) \cos \theta-\left(v_{w}-v\right) \sin \theta\right]=0 \\
\tau_{a y}+C_{w} \rho_{w}\left|\vec{u}_{w}-\vec{u}\right|\left[\left(v_{w}-v\right) \cos \theta+\left(u_{w}-u\right) \sin \theta\right]=0
\end{array} .\right.
$$

[31] Defining $V=C_{w} \rho_{w}\left|\vec{u}_{w}-\vec{u}\right|=C_{w} \rho_{w}\left[\left(u_{w}-u\right)^{2}+\right.$ $\left.\left(v_{w}-v\right)^{2}\right]^{\frac{1}{2}}$, we can solve equation (25) for $u$ and $v$ yielding

$$
\left\{\begin{array}{c}
u=u_{w}+\frac{1}{V}\left[\tau_{a x} \cos \theta+\tau_{a y} \sin \theta\right] \\
v=v_{w}-\frac{1}{V}\left[\tau_{a x} \sin \theta-\tau_{a y} \cos \theta\right]
\end{array},\right.
$$

where $V^{2}=C_{w} \rho_{w}\left(\tau_{a x}^{2}+\tau_{a y}^{2}\right)^{1 / 2}$. Figure 6a shows the distribution of $u$ for given $\phi=\theta=25^{\circ}$ and the water current velocity specified by equation (21). Given the same forcing conditions with a quadratic ocean drag in the ice model, UG-CICE can quickly converge toward the analytical solution (Figure 6b) in a timescale of $<1$ day. This is the first check for the UG-CICE formulation for stresses.

[32] We next reran UG-CICE with the same wind stress and water velocity but adding the internal ice stress for a time integration of 5 days. After 5 days, $u$ in the low ice concentration zone has the same pattern as the free drifting case, while in the high ice concentration zone connected to the eastern boundary, the ice velocity drops significantly due to viscosity (Figure 6c). A large gradient of $u$ appears in the transition between viscous and free-drifting zones. When the Coriolis force is added, a narrow low $u$ zone appears near the eastern boundary, but the general pattern remains unchanged (Figure 6d). For the cases shown in 


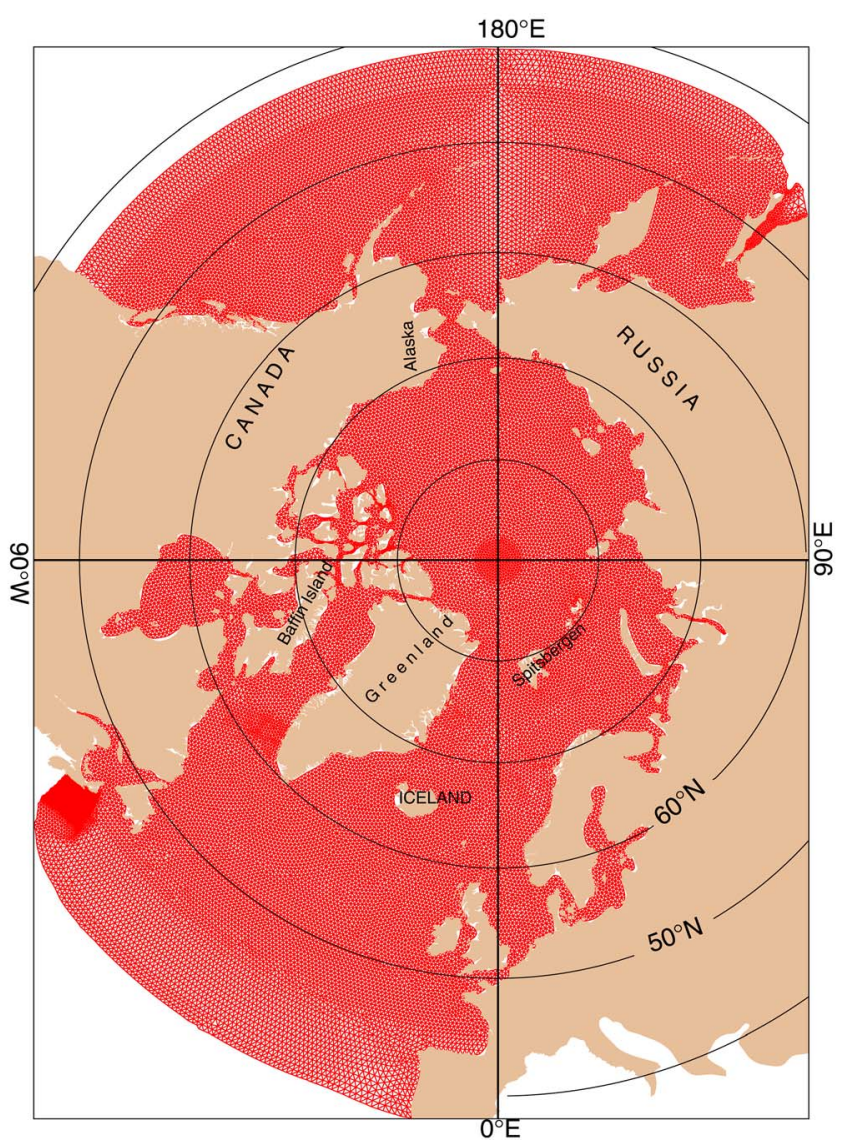

Figure 7. The coarse unstructured triangular grid configured for AO-FVCOM/UG-CICE. Total numbers of triangular cells and nodes are 55,508 and 29,043, respectively, with a horizontal resolution (measured by the side length of each triangle) varying from $3-5 \mathrm{~km}$ in the Canadian Archipelago, inlets and straits, and over the shelf break to $20-50 \mathrm{~km}$ in the interior basins.

Figures 6a-6c, the amplitudes of $u$ and $v$ are the same, while for the case with Coriolis force, the balance between the wind stress, ocean stress and internal ice stress is altered causing an adjustment in $u$ and $v$.

[33] Although our circular domain differs from the rectangular domain used by Hunke [2001], the characteristics of the ice velocity in these cases are the same for UG-CICE and CICE. This indicates that the ice dynamics incorporated in CICE remains unchanged when they are solved using the unstructured-grid, finite-volume algorithm developed for FVCOM.

\section{Application of UG-CICE to the Arctic Ocean}

\subsection{AO-FVCOM/UG-CICE and Design of Numerical Experiments}

[34] Based on the success in validating UG-CICE for the standard benchmark test problems presented above, we applied AO-FVCOM/UG-CICE to the Arctic Ocean. The focus here is to validate the capability of UG-CICE to capture the seasonal variability of the sea ice concentration, coverage and drift in the Arctic Ocean under "climatologic" forcing conditions. The "climatology" refers here to the meteorological forcing derived from the European Center for Medium-Range Weather Forecast (ECMWF) reanalysis ERA-15 over 1978-1994, with daily surface wind stress, net heat flux plus short-wave irradiance, precipitation minus evaporation, surface air temperature and pressure [source: Ocean Modeling Intercomparison Project (OMIP at website addressed http://www.omip.zmaw.de)]. This study was carried out with the understanding that the model fields predicted using "climatologic" forcing (based on averaging over the 15 year time series) should capture the "mean" seasonal variability in sea ice concentration, coverage and drift but not show the significant interannual variations that can occur in the Arctic Ocean.

[35] AO-FVCOM/UG-CICE is configured in the computational domain shown in Figure 7, which covers the entire Arctic Ocean and the Pan-Arctic region including the Canadian Archipelago, Hudson Bay, Baffin Bay, the Labrador Sea, the Nordic Sea and the Bering Sea. We call it the Pan-Arctic region that differs from the domain used in the previous AO-FVCOM tidal experiment described by Chen et al. [2009]. The domain has a horizontal resolution varying from $3 \sim 5 \mathrm{~km}$ in the Canadian Archipelago and the coastal region to $25 \sim 50 \mathrm{~km}$ in the interior. A hybrid coordinate is used in the vertical, with a total of 45 layers, 10 and 5 uniform ( $5 \mathrm{~m}$ thick) layers near the surface and bottom in the regions deeper than $225 \mathrm{~m}$, with a transition at this depth to the $\sigma$ coordinate in the shallow continental and coastal regions. The model bathymetry was interpolated from $2 \mathrm{~min}$ resolution IBCAO/NOAA and DBDBV/ONR databases. AO-FVCOM/UG-CICE was integrated numerically using the FVCOM semi-implicit solver with a time step of $600 \mathrm{~s}$. For UG-CICE, 120 integrations at a time step of $5 \mathrm{~s}$ were conducted to calculate internal ice stress.

[36] AO-FVCOM/UG-CICE is driven by (1) astronomic tidal forcing constructed using eight tidal constituents $\left(\mathrm{M}_{2}\right.$, $\mathrm{S}_{2}, \mathrm{~N}_{2}, \mathrm{~K}_{2}, \mathrm{~K}_{1}, \mathrm{P}_{1}, \mathrm{O}_{1}$, and $\mathrm{Q}_{1}$ ), (2) climatologic surface forcing (wind stress, net heat flux plus short-wave irradiance, sea level atmospheric pressure gradient, precipitation minus evaporation, sea surface air temperature, specific humidity and total cloud cover), and (3) river discharges. Boundary forcing of the domain are specified through oneway nesting with Global-FVCOM driven by the same forcing as $\mathrm{AO}-\mathrm{FVCOM} / \mathrm{UG}-\mathrm{CICE}$. Global-FVCOM includes 406 river inputs around the coast. The river discharges along the U.S. and Canadian coasts are specified by the daily climatologic means from USGS monitoring sites (source: http:// www.usgs.gov and www.ec.gc.ca), while the data outside the U.S. and Canada are provided by L. F. Smedstad (NCOM Group, personal communication, 2006). Temperature and salinity were initialized using the January global climatologic fields that in the Arctic Ocean region were constructed using the Polar Science Center Hydrographic climatology (PHC3.0) [Steele et al., 2001]. UG-CICE was initialized using a default setup of CICE, with five uniform categories and $2.53 \mathrm{~m}$ mean ice thickness covering the ocean north of $70^{\circ} \mathrm{N}$. Global-FVCOM was first spin up for a 50 year period and all variables in the nesting boundary cells at every time step for the 50 years were saved into the nesting module file, which was then used to drive AOFVCOM/UG-CICE. With the initial and boundary conditions from Global-FVCOM, AO-FVCOM/UG-CICE can be 

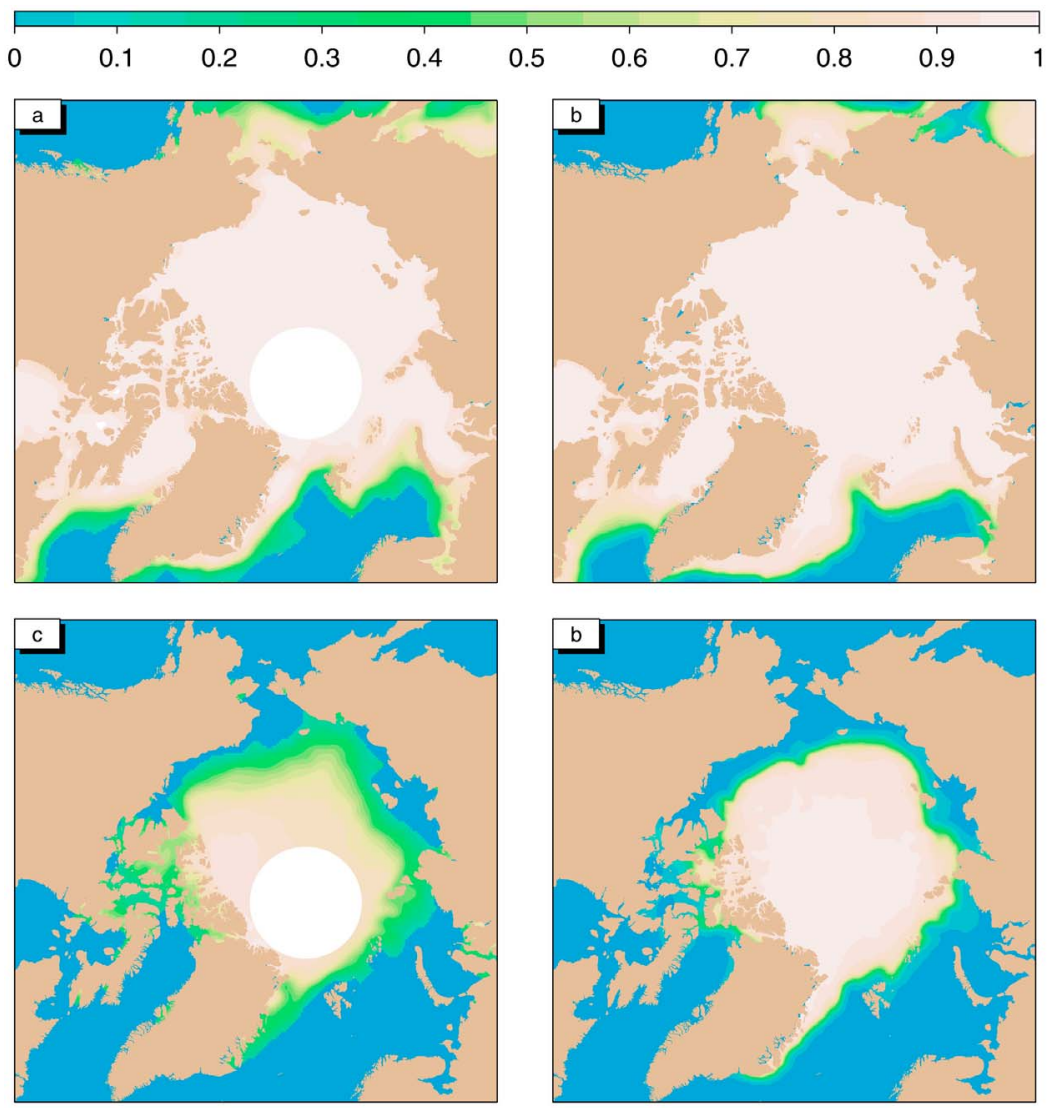

Figure 8. Comparison between distributions of ( $b$ and d) UG-CICE-calculated and (a and c) satellitederived monthly ice concentration for March (Figures 8a and 8b) and September (Figures 8c and 8d).

spin up for our "climatologic" forcing conditions within 5 years.

[37] It should be noted here that for this experiment, Global-FVCOM and AO-FVCOM use the same time step, which can be run with a single grid with no nesting. The reason for choosing this nesting approach is to make AOFVCOM run more efficiently and have the flexibility of refining the horizontal grid locally without the need to rerun the global scale domain.

\subsection{Model-Data Comparison for Ice Concentration and Drift Velocity}

[38] The AO-FVCOM/UG-CICE results for the 6 year simulation were compared with the observed ice concentration and drift velocity data averaged over the time period 1979-1994. The observational data were obtained from the National Snow and Ice Data Center (NSIDC). NSIDC has two types of sea ice time series data sets (GSFC and Bootstrap) derived from the same satellite measurements but using two different channel data and algorithms [Cavalieri et al., 2008; Comiso, 2008]. The difference of data sets for these two algorithms was described by Johnson et al. [2007], which shows that the Bootstrap data set provides better agreement with field measurements during the summertime ice-melting period. We selected the Bootstrap data set for our model-data comparison.

[39] UG-CICE provides reasonable agreement with the monthly averaged ice concentration in the Arctic Basin, Canadian Archipelago, and Hudson/Baffin Bay. Examples

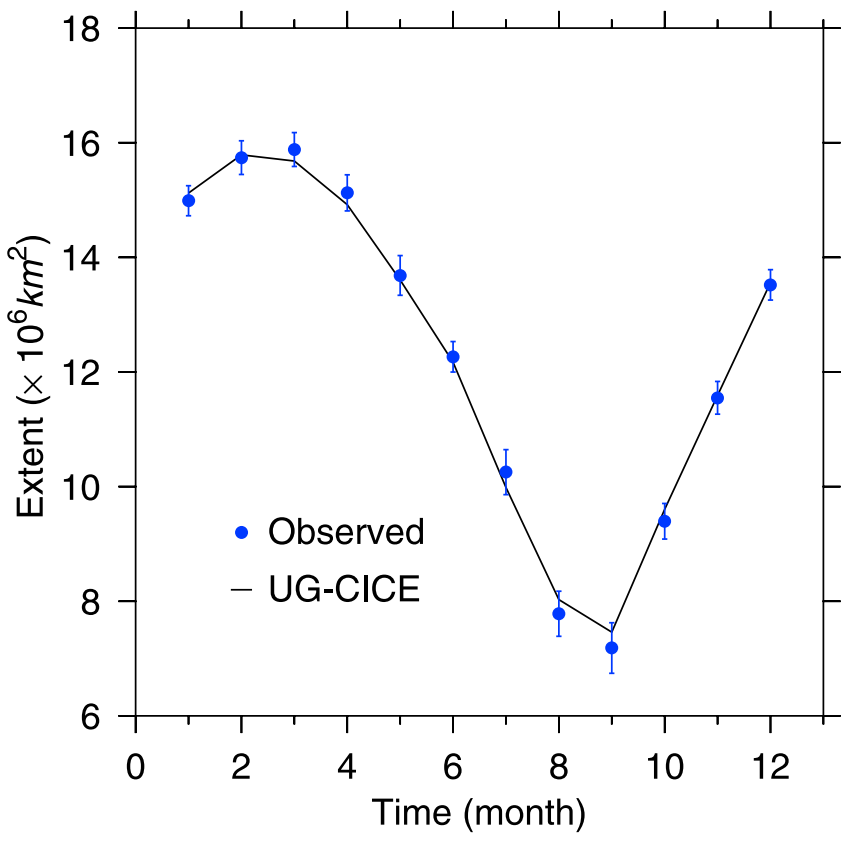

Figure 9. Comparison of the UG-CICE-calculated monthly ice extent with the observation estimated by the satellitederived data averaged over 1979-1994. Solid line is UG-CICE, circles are observation, and the error bars on the circles are the root square mean deviation relative to the monthly mean value. 


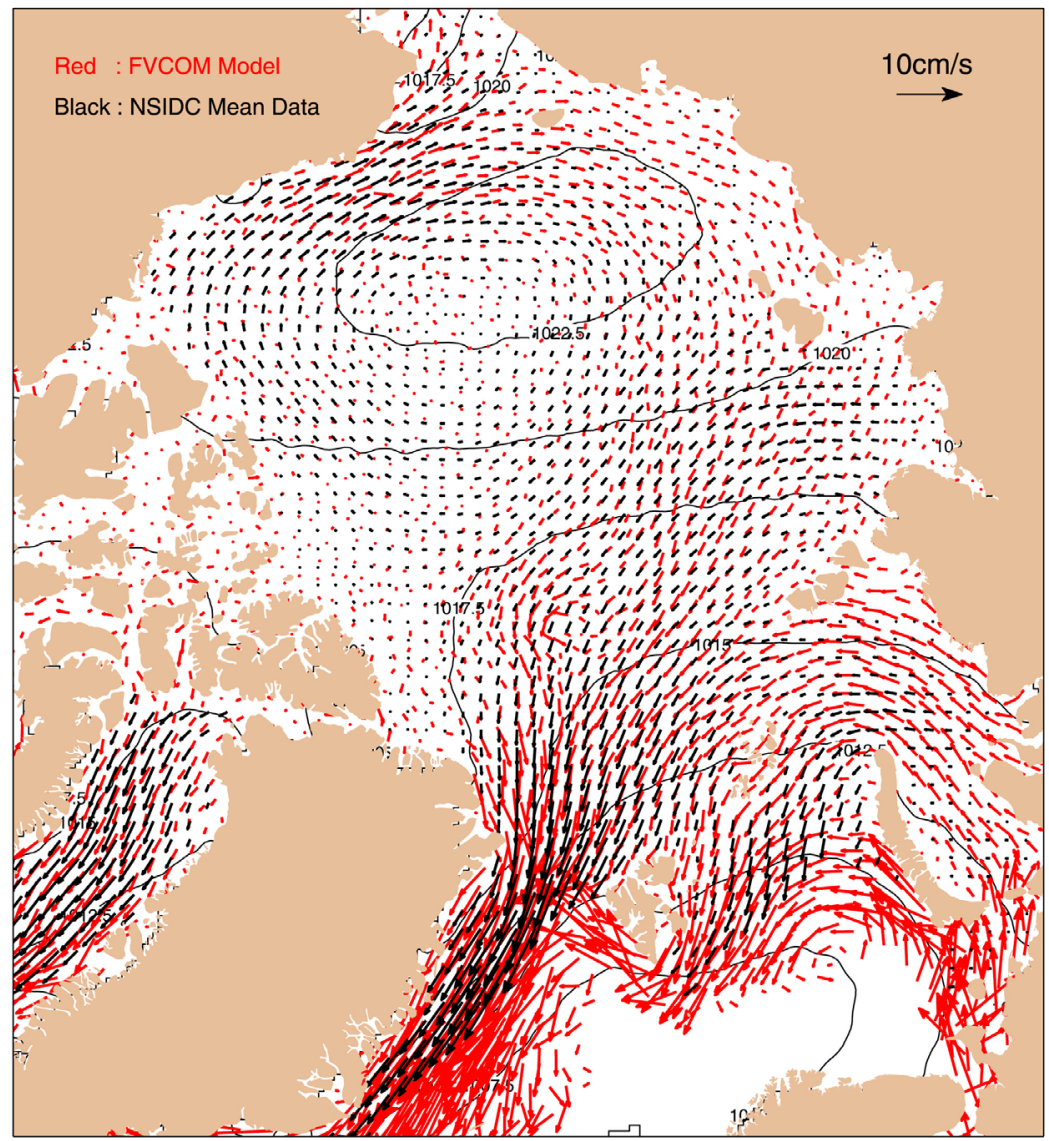

Figure 10. Comparison between March monthly mean ice-drifting velocities computed by UG-CICE and derived from the satellite data averaged over 1979-1994. Black vectors are satellite data, red vectors are UG-CICE, and black contour is the mean air pressure.

are presented in Figure 8 for March and September. In March, the satellite-derived data (Figure 8a) show that the entire Arctic is covered by ice and open water boundaries in the lower region of Baffin Bay and off the slope of Greenland. This distribution is well captured with UG-CICE (Figure 8b), except the model overestimates the ice coverage in the marginal ice zone around Greenland. In September, the satellite-derived data (Figure 8c) show that the Hudson/ Baffin Bay, Alaskan coast, and Russian coast are free of ice and the ice concentration in the Canadian Archipelago is much reduced. This ice distribution pattern is captured by UG-CICE (Figure 8d). Similar to March, UG-CICE underestimates the ice melting in the marginal ice zone around Greenland.

[40] We believe that the overestimate of the ice concentration in the marginal ice zone in UG-CICE is due to the lack of interannual variability of the ice concentration in our experiment due to our use of "climatologic" forcing conditions. The observed ice concentration distributions shown in Figure 8 were constructed by averaging the monthly satellite-derived data for the 15 year period 1979-1994. The satellite-derived ice concentration data exhibit a significant interannual variability in the marginal ice zone, which can be seen in the root-mean-square deviation of ice extent that counted the ice cover area with ice concentration exceeds
15\% (Figure 9). This interannual variation was not resolved in our experiment using the climatologic forcing. Taking this variation into consideration, UG-CICE is robust to capture the seasonal variability in the ice concentration in the Arctic region (Figure 9).

[41] The ice-drift velocity is an important variable used in validating a coupled ice-current model, since the ice is moved by combined surface winds and ocean currents. The redistribution process of the ice can directly influence the heat and salt transports. Observations of ice drift can be traced back to the Arctic expedition age one century ago, however, routine measurement from satellites started in the late 1970s. The NSIDC ice-drift velocity data were derived from successive satellite images [Emery et al., 1997] combined with the International Arctic Buoy Program (IABP) through an optimal interpolation approach. The resolution of this product is $25 \mathrm{~km}$, which started in 1979 and continues to the present. The monthly fields averaged over 1979-1994 are used here to compare with UG-CICE results. To provide a clear view, both satellite- and UG-CICE-derived ice-drift velocities were resampled with a $50 \mathrm{~km}$ resolution.

[42] AO-FVCOM/UG-CICE provides a reasonable simulation of the seasonal variability of ice-drift velocity in the Arctic region, particularly for the anticyclonic gyre, transpolar ice drift and ice export through Fram Strait. Direct 


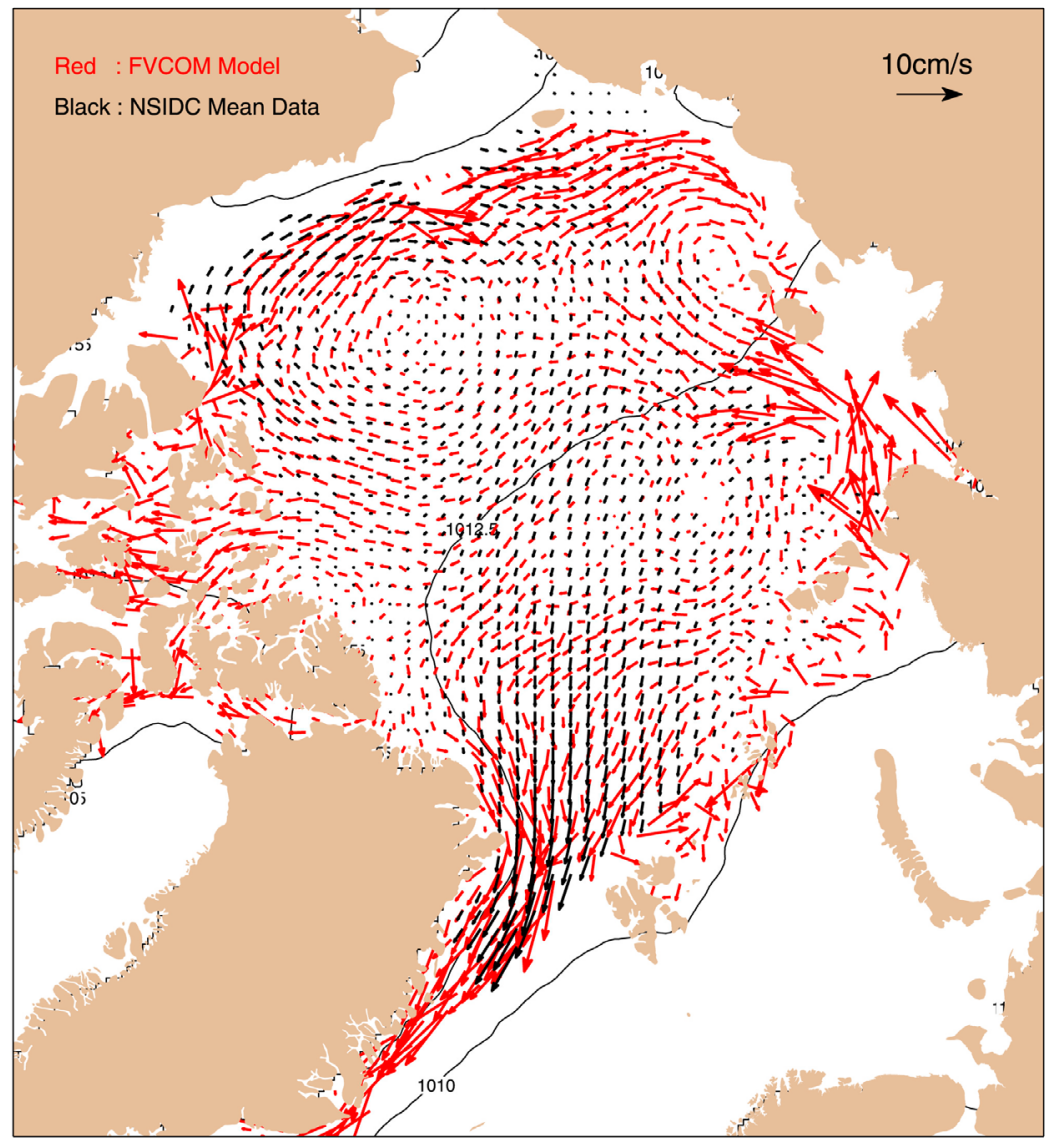

Figure 11. Comparison between September monthly mean ice-drifting velocities computed by UG-CICE and derived from the satellite data averaged over 1979-1994. Black vectors are satellite data, red vectors are UG-CICE, and black contour is the mean air pressure.
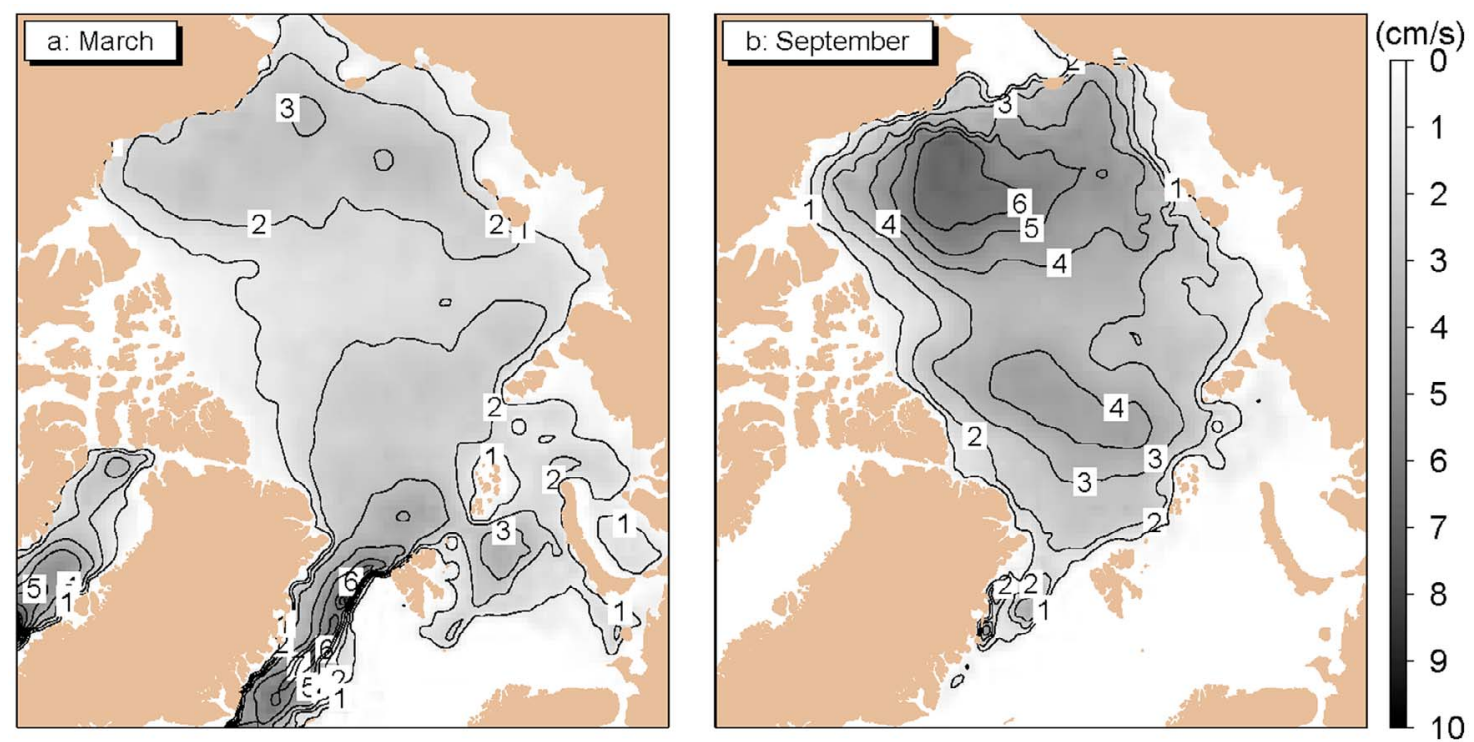

Figure 12. Distributions of the root square mean deviation of the satellite-derived ice-drifting velocity over 1979-1994 for (a) March and (b) September. 

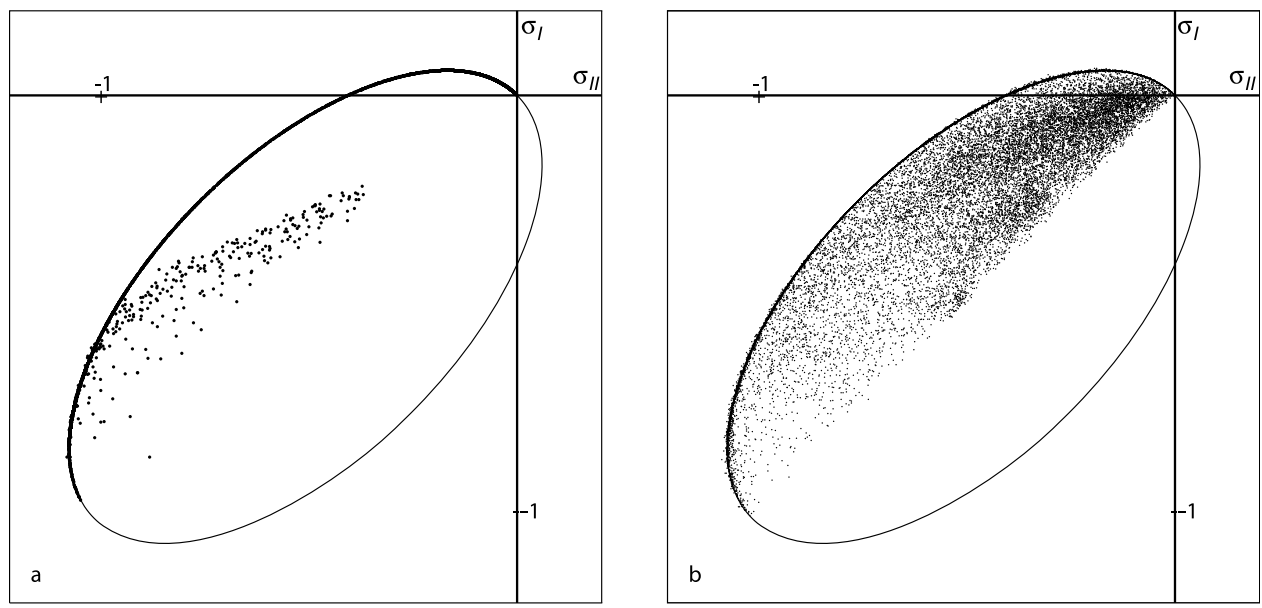

Figure 13. Distributions of normalized principal components of stress for (a) the benchmark test case 3 with the inclusion of the Coriolis force and (b) the Arctic Ocean application case described in section 4. The values of principal stress in Figure $1 \mathrm{~b}$ were picked at every fifth node point at a random time.

model-data comparisons were made for each month and examples for March and September are shown in Figures 10 and 11, respectively. In March, the model captures the anticyclonic drift pattern in the interior Arctic Ocean consistent with the high air pressure center (shown by the black contours), with intensified drift velocities around the Alaska and Greenland shelf as well as in Baffin Bay. Similar agreement is also found in September, during which the anticyclonic ice-drift gyre shrunk significantly as the ice melt over the shelf.

[43] As with ice concentration, AO-FVCOM/UG-CICE also shows a significant difference from the satellite-derived ice-drift velocity in the ice marginal zone. The satellitederived ice-drift velocity field exhibited a significant interannual variability consistent with the variability of the ice concentration [Rampal et al., 2009]. Figure 12 shows the root-mean-square deviation estimated by $\sqrt{\sigma_{u}^{2}+\sigma_{v}^{2}}$ where $\sigma_{u}$ and $\sigma_{v}$ are the monthly root-mean-square deviations for $x$ and $y$ components of the ice-drift velocity over 1979-1994. The poor agreement between the model and data appears in the region marked with significant interannual deviation. Although the measurement uncertainty could also contribute to the deviation, we believe that this deviation mainly counts for the interannual variability of the ice-drifting velocity. If that is the case, AO-FVCOM/UG-CICE is robust to capture the seasonal variability of the ice-drifting velocity in the Arctic region.

[44] It should be noticed here that the model-data comparison is made without considering the uncertainties in the satellite-derived ice data and meteorological forcing. Hunke and Holland's [2007] studies suggested that the variance of external forcing could significantly influence the results of numerical simulation in the Arctic Ocean. Johnson et al. [2007] compared GSFC, Bootstrap, Hadley Center and Walsh data sets for ice concentration and coverage and found remarkable differences, even though they came from the same raw data source. The vertical atmospheric water vapor content and melting surface of sea ice/snow can restrict the retrieval of reliable ice-drift velocity using passive microwave radiometers [Kwok et al., 1998]. Martin and
Gerdes [2007] compared the satellite-derived ice drift and the IABP ice-drifter velocities. Both data generally agreed well in speed, but it did show a noticeable difference in the drifting direction.

\section{Discussion}

[45] In addition to ice concentration, coverage and velocity, the relationship of the principal components of stress in the ice model is a key criterion to evaluate the reality and accuracy of an ice model [Zhang and Hibler, 1997; Zhang and Rothrock, 2000; Hunke, 2001]. Due to the strong nonlinearity in the viscous-plastic dynamics, the internal stresses, strain rates and viscosities need to be solved through iteration with a smaller time step to make them all converge to the elliptical yield curve [Hunke, 2001]. We solve the ice momentum and internal stress equations in a subcycling time step of $\Delta t_{e}$ with iterations of $N_{\mathrm{d}}=120$. Figure 13 shows the normalized principal components of stress for the benchmark test case 3 with inclusion of the Coriolis force (described in section 3) and the real application case for the Arctic Ocean sea ice simulation (described in section 4). In our calculation, $\sigma_{I}$ and $\sigma_{I I}$ are the eigenvalues of the stress tensor $\sigma_{i j}$ divided by the pressure $P$. In the Arctic Ocean case, we pick up the stress states every 5 nodes at a random simulation time. Both cases show the principal components of the stress from UG-CICE lay on or inside the elliptical yield curve, which suggests that the numerical algorithm used in the UG-CICE captures the nonlinear viscous-plastic ice dynamics.

\section{Summaries and Conclusion}

[46] UG-CICE was developed by converting CICE into an unstructured-grid, finite-volume version of CICE under the FVCOM framework, and implemented into the FVCOM model system for ice simulation in the Arctic Ocean. The model has been validated for three idealized benchmark test problems and then used to simulate the seasonal variability in ice concentration, coverage and drift velocity in the Arctic and its adjacent regions. 
[47] For the given same rectangular domain, UG-CICE configured with unstructured triangular grid is capable of reproducing the results of CICE. The finite-volume algorithm used in UG-CICE provides a better resolution of the sharp velocity change in the transition zone. For an application of AO-FVCOM/UG-CICE to the Arctic region, driven by "climatologic" meteorological forcing, tides and river discharge, the model is robust to capture the seasonal variability of the sea ice concentration, coverage and drift velocity within the interannual variation range.

[48] Our present work is focused on development and validation of UG-CICE in the FVCOM model system. However, the satellite-derived daily and monthly fields of the ice concentration and drift velocity clearly show a significant interannual variability. Based on the results presented here, the AO-FVCOM/UG-CICE system is well suited to investigate the seasonal and interannual variability of the ice field in the Arctic Ocean under realistic forcing conditions.

[49] Acknowledgment. This work was supported by the NSF Arctic Program for projects with grant numbers of ARC0712903, ARC0732084, and ARC0804029. The Arctic Ocean Model Intercomparison Project (AOMIP) has provided an important guidance for model improvements and ocean studies under coordinated experiments activities. We would like to thank AOMIP PI Proshutinsky for his valuable suggestions and comments on the ice dynamics. His contribution is supported by ARC0800400 and ARC0712848. The development of FVCOM was supported by the Massachusetts Marine Fisheries Institute NOAA grants DOC/NOAA NA04NMF4720332 and DOC/NOAA/NA05NMF4721131; the NSF Ocean Science Program for projects of OCE-0234545, OCE-0227679, OCE0606928, OCE-0712903, OCE-0726851, and OCE-0814505; MIT Sea Grant funds (2006-RC-103 and 2010-R/RC-116); and NOAA NERACOOS Program for the UMASS team. G. Gao was also supported by the Chinese NSF Arctic Ocean grant under contract 40476007. C. Chen's contribution was also supported by Shanghai Ocean University International Cooperation Program (A-2302-10-0003), the Program of Science and Technology Commission of Shanghai Municipality (09320503700), the Leading Academic Discipline Project of Shanghai Municipal Education Commission (J50702), and Zhi jiang Scholar and 111 project funds of the State Key Laboratory for Estuarine and Coastal Research, East China Normal University (ECNU). We want to acknowledge Elizabeth Hunke and William H. Lipscomb for generously sharing their benchmark test case configurations and helpful comments.

\section{References}

Cavalieri, D., C. Parkinson, P. Gloersen, and H. J. Zwally (2008), Sea Ice Concentrations From Nimbus-7 SMMR and DMSP SSM/I Passive Microwave Data, 1978-1994, http://nsidc.org/data/docs/daac/ nsidc0051_gsfc_seaice.gd.html, Natl. Snow and Ice Data Cent., Boulder, Colo.

Chen, C., H. Liu, and R. Beardsley (2003), An unstructured grid, finitevolume, three-dimensional, primitive equations ocean model: Application to coastal ocean and estuaries, J. Atmos. Oceanic Technol., 20 , 159-186, doi:10.1175/1520-0426(2003)020<0159:AUGFVT $>2.0$ CO 2 .

Chen, C., G. Cowles, and R. C. Beardsley (2006), An unstructured grid, finite-volume coastal ocean model: FVCOM user manual, 2nd ed., Tech. Rep. 06-0602, 315 pp., Sch. of Mar. Sci. and Technol., Univ. of Mass., Dartmouth, Mass.

Chen, C., H. Huang, R. C. Beardsley, H. Liu, Q. Xu, and G. Cowles (2007), A finite-volume numerical approach for coastal ocean circulation studies: Comparisons with finite difference models, J. Geophys. Res., 112, C03018, doi:10.1029/2006JC003485.

Chen, C., G. Gao, J. Qi, A. Proshutinsky, R. C. Beardsley, Z. Kowalik, H. Lin, and G. Cowles (2009), A new high-resolution unstructured grid finite volume Arctic Ocean model (AO-FVCOM): An application for tidal studies, J. Geophys. Res., 114, C08017, doi:10.1029/2008JC004941.

Comiso, J. (2008), Bootstrap Sea Ice Concentrations From NIMBUS-7 SMMR and DMSP SSM/I, November 1978 to December 1994, http:// nsidc.org/data/nsidc-0079.html, Natl. Snow and Ice Data Cent., Boulder, Colo.

Connolley, W. M., J. M. Gregory, and E. Hunke (2004), On the consistent scaling of terms in the sea-ice dynamics equation, J. Phys. Oceanogr. 34, 1776-1780, doi:10.1175/1520-0485(2004)034<1776:OTCSOT>2.0. $\mathrm{CO} ; 2$.

Emery, W. J., C. W. Fowler, and J. A. Maslanik (1997), Satellite-derived maps of Arctic and Antarctic sea ice motion: 1988 to 1994, Geophys. Res. Lett., 24, 897-900, doi:10.1029/97GL00755.

Gao, G., C. Chen, and R. C. Beardsley (2010), An unstructured-grid Arctic Ocean model system (AO-FVCOM): A study of ice-ocean interaction, paper presented at 2010 Ocean Science Meeting, Adv. the Sci. of Limnol. and Oceanogr., Portland, Oreg., 22-26 Feb.

Golubeva, E. N., and G. A. Platov (2007), On improving the simulation of Atlantic Water circulation in the Arctic Ocean, J. Geophys. Res., 112, C04S05, doi:10.1029/2006JC003734

Häkkinen, S., and A. Proshutinsky (2004), Freshwater content variability in the Arctic Ocean, J. Geophys. Res., 109, C03051, doi:10.1029/2003JC001940.

Hibler, W. D. (1979), A dynamic thermodynamic sea ice model, J. Phys. Oceanogr., 9, 815-846, doi:10.1175/1520-0485(1979)009<0815: ADTSIM $>2.0 . \mathrm{CO} ; 2$.

Huang, H., C. Chen, G. W. Cowles, C. D. Winant, R. C. Beardsley, K. S. Hedstrom, and D. B. Haidvogel (2008), FVCOM validation experiments: Comparisons with ROMS for three idealized barotropic test problems, J. Geophys. Res., 113, C07042, doi:10.1029/2007JC004557.

Hunke, E. C. (2001), Viscous-plastic sea ice dynamics with the EVP model: Linearization issues, J. Comput. Phys., 170, 18-38, doi:10.1006 jcph.2001.6710

Hunke, E. C., and J. K. Dukowicz (1997), An elastic-viscous-plastic model for sea ice dynamics, J. Phys. Oceanogr., 27, 1849-1867, doi:10.1175/ 1520-0485(1997)027<1849:AEVPMF>2.0.CO;2.

Hunke, E. C., and J. K. Dukowicz (2002), The elastic-viscous-plastic sea ice dynamics model in general orthogonal curvilinear coordinates on a sphere-Incorporation of metric terms, Mon. Weather Rev., 130, 1848-1865, doi:10.1175/1520-0493(2002)130<1848:TEVPSI $>2.0 . C O ; 2$

Hunke, E. C., and M. M. Holland (2007), Global atmospheric forcing data for Arctic-ice-ocean modeling, J. Geophys. Res., 112, C04S14, doi: $10.1029 / 2006 \mathrm{JC} 003640$

Hunke, E. C., and W. H. Lipscomb (2006), CICE: The Los alamos sea ice model documentation and software user's manual, report, Los Alamos Natl. Lab., Los Alamos, N. M.

Johnson, M., S. Gaffigan, E. Hunke, and R. Gerdes (2007), A comparison of Arctic Ocean sea ice concentration among the coordinated AOMIP model experiments, J. Geophys. Res., 112, C04S11, doi:10.1029/ 2006JC003690.

Kliem, N., and D. A. Greenberg (2003), Diagnostic simulations of the summer circulation in the Canadian Arctic Archipelago, Atmos. Ocean, 41, 273-289, doi:10.3137/ao.410402

Kobayashi, M. H., J. M. C. Pereira, and J. C. F. Pereira (1999), A conservative finite-volume second-order-accurate projection method on hybrid unstructured grids, J. Comput. Phys., 150, 40-75, doi:10.1006/ jcph.1998.6163

Kowalik, Z., and A. Proshutinsky (1994), The Arctic Ocean tides, in The Polar Oceans and Their Role in Shaping the Global Environment, Geophys. Monogr. Ser., vol. 85, edited by O. M. Johannessen et al., pp. 137-158, AGU, Washington, D. C.

Kwok, R., A. Schweiger, D. A. Rothrock, S. Pang, and C. Kottmeier (1998), Sea ice motion from satellite passive microwave imagery assessed with ERS SAR and buoy motions, J. Geophys. Res., 103(C4), 8191-8214, doi:10.1029/97JC03334.

Lipscomb, W. H., E. C. Hunke, W. Maslowski, and J. Jakacki (2007), Ridging, strength, and stability in high-resolution sea ice models, J. Geophys. Res., 112, C03S91, doi:10.1029/2005JC003355.

Martin, T., and R. Gerdes (2007), Sea ice drift variability in Arctic Ocean Model Intercomparison Project models and observations, J. Geophys. Res., 112, C04S10, doi:10.1029/2006JC003617.

Panteleev, G., A. Proshutinsky, M. Kulakov, D. Nechaev, and W. Maslowski (2007), Investigation of the summer Kara Sea circulation employing a variational data assimilation technique, J. Geophys. Res., 112, C04S15, doi:10.1029/2006JC003728.

Proshutinsky, A., and Z. Kowalik (2007), Preface to special section on Arctic Ocean Model Intercomparison Project (AOMIP) Studies and Results, J. Geophys. Res., 112, C04S01, doi:10.1029/2006JC004017.

Proshutinsky, A., et al. (2001), The Arctic Ocean Model Intercomparison Project (AOMIP), Eos Trans. AGU, 82(51), 637-644, doi:10.1029/ $01 \mathrm{EO} 00365$.

Proshutinsky, A., et al. (2005), Arctic Ocean study: Synthesis of model results and observations, Eos Trans. $A G U, 86(40), 368,371$, doi:10.1029/ 2005EO400003 
Rampal, P., J. Weiss, D. Marsan, and M. Bourgoin (2009), Arctic sea ice velocity field: General circulation and turbulent-like fluctuations, J. Geophys. Res., 114, C10014, doi:10.1029/2008JC005227.

Rothrock, D. A. (1975), The energetics of the plastic deformation of pack ice by ridging, J. Geophys. Res., 80, 4514-4519, doi:10.1029/ JC080i033p04514.

Steele, M., R. Morley, and W. Ermold (2001), PHC: A global ocean hydrography with a high quality Arctic Ocean, J. Clim., 14, 2079-2087, doi:10.1175/1520-0442(2001)014<2079:PAGOHW>2.0.CO;2.

Steiner, N., et al. (2004), Comparing modeled stream function, heat and freshwater content in the Arctic Ocean, Ocean Modell., 6, 265-284, doi:10.1016/S1463-5003(03)00013-1.

Thorndike, A. S., D. S. Rothrock, G. A. Maykut, and R. Colony (1975), The thickness distribution of sea ice, J. Geophys. Res., 80, 4501-4513, doi:10.1029/JC080i033p04501.
Zhang, J., and W. D. Hibler III (1997), On an efficient numerical method for modeling sea ice dynamics, J. Geophys. Res., 102, 8691-8702, doi:10.1029/96JC03744.

Zhang, J., and D. A. Rothrock (2000), Modeling Arctic sea ice with an efficient plastic solution, J. Geophys. Res., 105, 3325-3338, doi:10.1029/ 1999JC900320.

R. C. Beardsley, Department of Physical Oceanography, Woods Hole Oceanographic Institution, MS 21, Woods Hole, MA 02543, USA.

C. Chen, G. Gao, and J. Qi, School for Marine Science and Technology, University of Massachusetts Dartmouth, 706 South Rodney French Blvd. New Bedford, MA 02744, USA. (ggao@umassd.edu) 